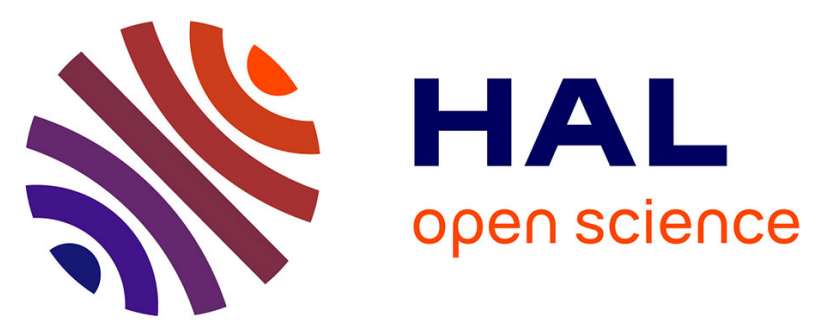

\title{
Effect of spirulina and silicon-enriched spirulina on metabolic syndrome features, oxidative stress and mitochondrial activity in Zucker fatty rats
}

Joris Vidé, Béatrice Bonafos, Gilles Fouret, François Casas, Bernard Jover, Nicolas Jouy, Christine Feillet-Coudray, Sylvie Gaillet, Charles Coudray, Christine Feillet-coudray

\section{To cite this version:}

Joris Vidé, Béatrice Bonafos, Gilles Fouret, François Casas, Bernard Jover, et al.. Effect of spirulina and silicon-enriched spirulina on metabolic syndrome features, oxidative stress and mitochondrial activity in Zucker fatty rats. Journal of Food Biochemistry, 2019, 43 (9), pp.e12979. 10.1111/jfbc.12979 . hal-02281123

HAL Id: hal-02281123

https://hal.science/hal-02281123

Submitted on 24 Jun 2020

HAL is a multi-disciplinary open access archive for the deposit and dissemination of scientific research documents, whether they are published or not. The documents may come from teaching and research institutions in France or abroad, or from public or private research centers.
L'archive ouverte pluridisciplinaire HAL, est destinée au dépôt et à la diffusion de documents scientifiques de niveau recherche, publiés ou non, émanant des établissements d'enseignement et de recherche français ou étrangers, des laboratoires publics ou privés. 


\title{
Effect of spirulina and silicon-enriched spirulina on metabolic syndrome features, oxidative stress and mitochondrial activity in Zucker fatty rats
}

\author{
Joris Vidé $^{1}$ | Béatrice Bonafos ${ }^{1}$ | Gilles Fouret ${ }^{1}$ | François Casas ${ }^{1}$ | Bernard Jover ${ }^{2}$ | \\ Nicolas Jouy $^{3}$ | Christine Feillet-Coudray ${ }^{1}$ | Sylvie Gaillet ${ }^{1}$ | Charles Coudray $^{1}$
}

${ }^{1}$ DMEM, INRA, University of Montpellier, Montpellier, France

${ }^{2}$ PhyMedExp, INSERM, CNRS, Université Montpellier, Montpellier, France

${ }^{3}$ Phyco-Biotech SAS, Montpellier, France

\section{Correspondence}

Charles Coudray, UMR 866 Dynamique du muscule aire \& Métabolisme, Centre INRA de Montpellier, 2 Place Viala, 34060 Montpellier, France.

Email: Charles.coudray@inra.fr

\section{Funding information}

The results of this work are part of the Spirulicium Cardio project co-funded by the Occitanie region (France) and by the European Regional Development Fund

\begin{abstract}
The use of Spirulina platensis (Sp) as a functional food was suggested decades ago. Biological incorporation of Silicon (Si) into Sp increases its bioavailability for potential food supplement applications. This work aimed at determining the effects of $S p$ and $\mathrm{Si}$-enriched $\mathrm{Sp}(\mathrm{Sp}+\mathrm{Si})$ on metabolic syndrome features in Zucker fatty rats. Thirty Zucker fatty rats were divided into three groups and supplemented with placebo or $\mathrm{Sp}$ or Sp+Si croquettes for 12 weeks. Food consumption, glucose intolerance, hepatic steatosis, and mitochondrial and oxidative stress were determined. Zucker fatty rats exhibited several hepatic metabolic alterations as well as mitochondrial and oxidative stress perturbations. The intake of Sp increased plasma TG levels and decreased the hepatic NADPH oxidase activity and ameliorated transitorily the glucose intolerance. However, Si-spirulina does not appear to have more beneficial effects than spirulina alone. Other experiments with different species of rats/mice, different diets, or durations of diet intake should be undertaken to confirm or infirm these results.

\section{Practical applications}

Glucose intolerance and hepatic steatosis, two major components of metabolic syndrome, are increasing and becomes a major public health issue. Use of Spirulina platensis $(\mathrm{Sp})$ as a functional food was suggested as a protein-dense food source. Bioavailable silicon (Si) may be an essential nutrient for higher animals, including humans. Sp but not Sp+Si decreased liver NADPH oxidase activity and improved transitorily glucose tolerance. This is the first study where $\mathrm{Sp}$ and $\mathrm{Sp}+\mathrm{Si}$ effect on glucose intolerance is reported in Zucker rat. Other experiments should be undertaken to confirm or infirm invalidate the beneficial effects of $\mathrm{Sp}+\mathrm{Si}$ supplement in the metabolic syndrome features.
\end{abstract}

KEYWORDS

mitochondrial activity, obesity disorders, oxidative stress, silicon, spirulina, Zucker rat 


\section{1 | INTRODUCTION}

Spirulina platensis $(\mathrm{Sp})$ and its processing products are employed in agriculture, food industry, pharmaceutics, perfumery, and medicine (Hosseini, Khosravi-Darani, \& Mozafari, 2013). Indeed, Sp has several pharmacological activities such as antimicrobial, anticancer, metalloprotective (Konickova et al., 2014), as well as immunostimulant and antioxidant effects due to its rich content of protein, polysaccharide, lipid, essential amino and fatty acids, dietary minerals, and vitamins (Lupatini, Colla, Canan, \& Colla, 2017). Recently, Sp supplementation at a dose of $1 \mathrm{~g} / \mathrm{d}$ for 12 weeks was showed to be effective in modulating body weight and appetite and partly modifies serum lipids in obese individuals (Zeinalian, Farhangi, Shariat, \& Saghafi-Asl, 2017). This can further confirm the efficacy of this herbal supplement in control and prevention of obesity and obesity-related disorders. Sp is particularly suitable for the production of specific bioactive compounds and nutritional elements, in particular minerals, that they are able to accumulate in an organically biotransformed form. Several reports have described successful enrichment of Sp biomass in selenium, iron, or chromium (Chen, Wong, \& Zheng, 2006). So, a new type of food supplements has thus been developed and could serve as a rich source of bioavailable trace elements (Cases et al., 2002; Mazo, Gmoshinski, \& Zorin, 2007).

Evidence exists indicating that Silicon (Si) may be an essential nutrient for higher animals, including humans (Price, Langford, \& Liporace, 2012). The biological importance of Si has to be considered in the context of its body specific distribution. The highest concentrations are found in bone and connective tissues, such as aorta, tendons, and skin, where Si appears to act positively on extracellular matrix turnover via collagen and elastin synthesis (Jugdaohsingh, Watson, Pedro, \& Powell, 2015). Indeed, Si supplementation has been reported to have beneficial effects on these tissues, especially bones and skin. In contrast, Si deficiency has been associated with detrimental effects on bone mineralization and growth and on skin elasticity and healing (Price, Koval, \& Langford, 2013).

The prevalence of major metabolic syndrome components, namely glucose intolerance and hepatic steatosis, diabetes, and cardiovascular diseases, is rapidly increasing and becomes a major public health issue (O'Neill \& O'Driscoll, 2015). The importance of Si has been indeed demonstrated in cardiovascular pathophysiology, namely in the prevention of atherosclerosis being highly concentrated in the aorta. Indeed, several studies have shown an inverse relationship between the ingestion of $\mathrm{Si}$ and the development of atherosclerosis (Loeper, Goy, Fragny, Troniou, \& Bedu, 1988). Furthermore, Si supplementation has been shown to reduce hypertension and increase antihypertensive and antiatherogenic gene expression in the aorta of spontaneously hypertensive rats (Maehira et al., 2011). Incorporating Si into Sp could so be a way to produce bioavailable Si-enriched food supplements. Therefore, and in line with the antioxidant, hypolipidemic, and antiinflammatory properties of $\mathrm{Sp}$ and the reported beneficial effects of Si, we undertook this work to determine the potential effects of $\mathrm{Sp}$ and $\mathrm{Sp}+\mathrm{Si}$ supplements on the major metabolic syndrome components, namely glucose intolerance and hepatic steatosis and their associated metabolic alterations, specifically inflammation, oxidative stress, and mitochondrial dysfunction, in a large chronic study of 12 weeks, in Zucker fatty rat. Our results showed that dietary intake of $\mathrm{Sp}$ but no $\mathrm{Sp}+\mathrm{Si}$ supplement could decrease the liver enzymatic activity of $\mathrm{NADPH}$ oxidase and improve transitorily glucose tolerance. However, Si supplementation of spirulina does not appear to have more beneficial/ adverse effects than spirulina alone.

\section{2 | MATERIALS AND METHODS}

\subsection{Animals and diets}

Thirty young male Zucker fatty rats (Charles River, L'Arbresle, France) aged 6 weeks (weighing 190-200 g) were housed (two per cage) under conditions of constant temperature $\left(20-22^{\circ} \mathrm{C}\right)$, humidity $(45 \%-50 \%)$, and a standard dark cycle $(20.00-08.00 \mathrm{hr})$. The rats were randomized into three groups of 10 animals each and fed for 12 weeks a semi-purified control diet (See Supplementary Table S1) and rats were supplemented with placebo or Sp or Sp+Si croquettes for 12 weeks. Our institution guidelines for the care and use of laboratory animals were observed and all experimental procedures were approved by the local ethical committee in Montpellier, France (Reference CEEA-LR-12002).

\section{2 | Preparation and administration of Sp and $\mathrm{Sp}+\mathrm{Si}$ croquettes}

$\mathrm{Sp}$ and $\mathrm{Sp}+\mathrm{Si}$ were produced and the administered croquettes were prepared by Phyco-Biotech, Lunel, France as previously described (Vide et al., 2018). Small croquettes of placebo, Sp, or Sp+Si (about $30 \mathrm{mg}$ ) were administered daily orally with a small forceps. The rats of each group received a placebo croquette (Zucker group), a Sp croquette ( $28.5 \mathrm{mg} / \mathrm{kg}$ body weight, Zucker+Sp group), or a $\mathrm{Sp}+\mathrm{Si}$ croquette (28.5 mg Sp with $0.57 \mathrm{mg} \mathrm{Si} / \mathrm{kg}$ body weight, Zucker+Sp+Si group). Sp dosage and its Si content (2\%) were determined according to previous studies (Vidé, Romain, et al., 2015) and this corresponds to daily intake of about 2,000 mg of Sp and $40 \mathrm{mg}$ of Si for a 70 kg-human (Reagan-Shaw, Nihal, \& Ahmad, 2008). Zucker rats were given free access to tap water and food and their body weight and food consumption were recorded weekly.

\section{3 | Oral glucose tolerance test}

The oral glucose tolerance test (OGTT) was performed in the middle and at the end of the study as previously described (Aoun et al., 2012). Briefly, 6-hr fasting rats received by gavage $2.5 \mathrm{~g}$ glucose/ $\mathrm{kg}$ body weight. Blood was collected through the tail vein of conscious rats immediately prior to the gavage, and 20,40, 60, 90, 120 , and 180 min afterward and blood glucose was measured on a whole blood drop using glucose strips and a commercial glucometer (ACCU-CHEK performa, Roche Diagnostics). The area under the curve $(A \cup C)$ values were calculated by the trapezium method. The AUC values are expressed as g glucose. $I^{-1} / 180 \mathrm{~min}$. 


\subsection{Animal sacrifice and blood and tissue sampling}

The $16 \mathrm{hr}$-fasted rats were anesthetized with pentobarbital (40 mg/ $\mathrm{kg}$ b.w) and blood was drawn from the inferior vena cava with $10 \mathrm{ml}$ syringes. Blood tubes were centrifuged at $1,000 \mathrm{~g}$ for $10 \mathrm{~min}$ at $4^{\circ} \mathrm{C}$, plasma or serum were collected and stored at $-80^{\circ} \mathrm{C}$ until analysis. Liver, muscles and adipose tissue were removed, rinsed with $0.9 \%$ of $\mathrm{NaCl}$, weighed and frozen in $\mathrm{N} 2$ and kept at $-80^{\circ} \mathrm{C}$ until analyses.

\section{5 | Blood biochemical analyses}

Plasma glucose levels were measured by enzymatic techniques (Konelab, Thermo Electron Corp, Vantaa, Finland). Plasma levels of insulin, leptin, adiponectin (Linco Research, St Charles, Missouri, USA) and IL-6, TNF-a, and MCP-1 (Invitrogen, Life Technologies, Cergy Pontoise, France) were quantified with ELISA kits according to the manufacturers' instruction. Insulin resistance (IR) was evaluated by the homeostasis model of IR (HOMA-IR) formula: [(fasting plasma glucose level, $\mathrm{mmol} / \mathrm{L} \times$ fasting plasma insulin level, $\mathrm{mIU} / \mathrm{L}) / 22.5]$.

\subsection{Blood and liver lipid levels and histological analysis}

Serum levels of total cholesterol, triglycerides (TG), and free fatty acids (FFA) were measured by enzymatic techniques (Konelab, Thermo Electron Corp, Vantaa, Finland).

Liver samples were homogenized in $0.9 \% \mathrm{NaCl}$ solution containing $0.1 \%$ of Triton $\mathrm{X}-100$ using a Polytron homogenizer. Total cholesterol, TG, and FFA levels were quantified on the liver homogenate by enzymatic methods (Cholesterol RTU kit; TAG PAP kit, Biomerieux, Lyon, France and Wako-NEFA-C kit, Oxoid, Dardilly, France).

For microscopic studies, liver samples were frozen-fixed and 5micron serial tissue sections were processed. Liver injury, such as steatosis, was evaluated by histological examination after Oil Red $O$ (ORO) staining as previously described (Djohan et al., 2018). Results are expressed as the percentage of total area within the field stained by ORO. At least 10 fields per sample have been examined and scored.

\subsection{Enzymatic activitiy of hepatic NADPH oxidase}

NADPH oxidase dependent-superoxide anion production was determined on rat liver samples as previously described (Feillet-Coudray et al., 2009). Briefly, liver homogenates were incubated at $37^{\circ} \mathrm{C}$ for $30 \mathrm{~min}$ in the presence or absence of Diphenyleneiodonium (DPI), a NADPH oxidase inhibitor. Lucigenin-enhanced chemiluminescence was assessed to determine $\mathrm{O}_{2}^{--}$generation after adding $\mathrm{NADPH}$, the substrate for NADPH oxidase. The chemiluminescence signals were measured by a microplate luminometer LB96V (Berthold Technologies, Yvelines, France). The results were expressed as relative light units (RLU) and were corrected for protein concentration.

\section{8 | Liver mitochondrial respiratory complex activities}

Citrate synthase (CS) activity was measured according to Srere (1969). The enzymatic activity of the complex I was measured according to Janssen et al. (2007), the complex II (CII) and the complex II+III (CII+CIII) according to Rustin et al. (1994) and the cytochrome c oxidase (COX) was measured according to Wharton and Tzagoloff (1967) by following the oxidation of Cytochrome $C$ at $550 \mathrm{~nm}$. In addition, the enzymatic activity $\beta$-hydroxyacyl-CoA dehydrogenase ( $\beta$ HAD) was determined by a spectrophotometric technique according to Clayton et al. (2001).

\subsection{Blood and liver oxidative stress parameters}

Thiobarbituric acid-reactive substances (TBARS), representing lipid peroxidation levels, were measured in plasma according to the method of Yagi (1984) and in liver homogenates according to the method of Sunderman, Marzouk, Hopfer, Zaharia, and Reid (1985). Protein oxidation was assessed in plasma and liver supernatant by measuring the sulfhydryl groups using the Ellman reagent (Jocelyn, 1987). Advanced oxidation protein product was assessed by monitoring the optical density at $430 \mathrm{~nm}$ after simple dilution in PBS-acetic acid buffer (Witko-Sarsat et al., 1998).

Total glutathione (GSH) and oxidized GSH (GssG) were measured in blood and liver homogenate according to the method of Griffith (1980). Catalase activity was measured in red blood cells (RBC) and liver supernatant according to the method of Beers and Sizer (1952). Glutathione peroxidase (GPx) was measured in plasma and liver supernatant according to the method of Flohe and Gunzler (1984). Superoxide dismutase were measured in plasma and liver supernatant according to the method of Marklund (1976).

\subsection{0 | Real-time quantitative RT-qPCR analysis}

Gene expression of major players of lipid metabolism and redox status was measure by real-time Quantitative Polymerase Chain Reaction (RT-qPCR). Liver total RNA was extracted with Trizol reagent (Invitrogen Life Technologies, Cergy Pontoise, France). Reverse transcription reaction was performed with $2 \mu \mathrm{g}$ total RNA. cDNA was synthesized with the use of SuperScript II Reverse Transcriptase for first strand cDNA synthesis (Invitrogen Life Technologies, Cergy Pontoise, France) and Oligo (dT) primers. The mRNA expressions of target genes were determined by RT-qPCR, using IQTM SYBR Green Supermix (Biorad, Hercules, CA, USA) with a MiniOpticon detection system (Biorad, Hercules, CA, USA). Data were normalized to Ppia used as reference gene. The primer sequences used for real-time RTPCR are shown in the supplementary Table S2.

\subsection{1 | Statistical analysis}

Data are expressed as means $\pm S D$ with $n=9-10$ animals per group. One-way ANOVA test, with the Fischer test as a posttest, was 
used to detect statistical significance among the four experimental groups. The limit of statistical significance was set at an $\alpha$ level of $p<0.10$. Means in a row with different letters differ. Statistical analysis data was performed using the StatView program (SAS Institute, Cary, NC, USA).

\section{3 | RESULTS}

\subsection{Dietary consumption and rat body and organs weights}

The cumulative dietary intake (g/rat) of the three groups is shown in the Figure 1a. The daily dietary intake (g/day/rat) was tended to decrease with $\mathrm{Sp}$ and $\mathrm{Sp}+\mathrm{Si}$ supplements (1B). The slight decrease in dietary intake, observed on the Figure 1b, was without significant effect on the body weight evolution during this study (Figure 2a). Indeed, the final body weight as well as the body weight gain remained unchanged among the three groups (Figure $2 b, c$ ). As expected, liver and adipose tissue weights were markedly high in the Zucker rats (about $25 \mathrm{~g}$ each) but the Sp or Sp-Si supplements had shown no significant effect on these two parameters (Figure $2 \mathrm{~d}, \mathrm{e}$ ).

\section{2 | Glucose tolerance and blood lipid parameters}

Oral glucose tolerance test (OGTT) was carried out twice; at the 6th and the 11th weeks of diet. The Figure $3 a, b$ show the blood glucose evolution after oral glucose gavage. During the first OGTT test, the area under the curve (AUC) was significantly decreased with the Sp diet compared to the other two groups. However, neither Sp nor
$\mathrm{Sp}+\mathrm{Si}$ supplement was efficient to modify this parameter during the second OGTT test.

As shown in Table 1, $\mathrm{Si}$ and $\mathrm{Sp}+\mathrm{Si}$ supplements remained without effect on blood levels of glucose, insulin, and as well as leptin and adiponectin. Consequently, HOMA-IR index remained statistically unchanged (Table 1). Surprisingly, blood TG levels were increased with the Sp diet but not with the Sp+Si diet compared to the Zucker rats, whereas blood cholesterol and FFA levels remained statistically unchanged (Table 1). In line with this, both $\mathrm{Si}$ and $\mathrm{Sp}+\mathrm{Si}$ supplements did not affect the enzymatic activtity of the blood paraoxonase. Indeed, plasma paraoxonase, bound to high-density lipoproteins (HDL), prevents the oxidation of LDL, and scavenges oxidized phospholipids, thus protecting from atherogenesis.

\subsection{Hepatic lipids and steatosis and liver integrity}

Liver levels of cholesterol, TG, and FFA as well as plasma activity of alanine transaminase (ALAT) remained statistically similar within the three studied diets. Table 1). In agreement with the above results, the liver histological staining with Oil Red $O$, reflecting steatosis, did not show any significant difference among the studied groups (Figure 4). More specifically, both $\mathrm{Sp}$ and $\mathrm{Sp}+\mathrm{Si}$ supplements had no significant effect although they tended to improve the later parameter.

\section{4 | Liver and muscle mitochondrial activity}

The liver enzymatic activity of citrate synthase as well as that of the complexes I, II, II+III, and IV remained unchanged among the three (a)

2000

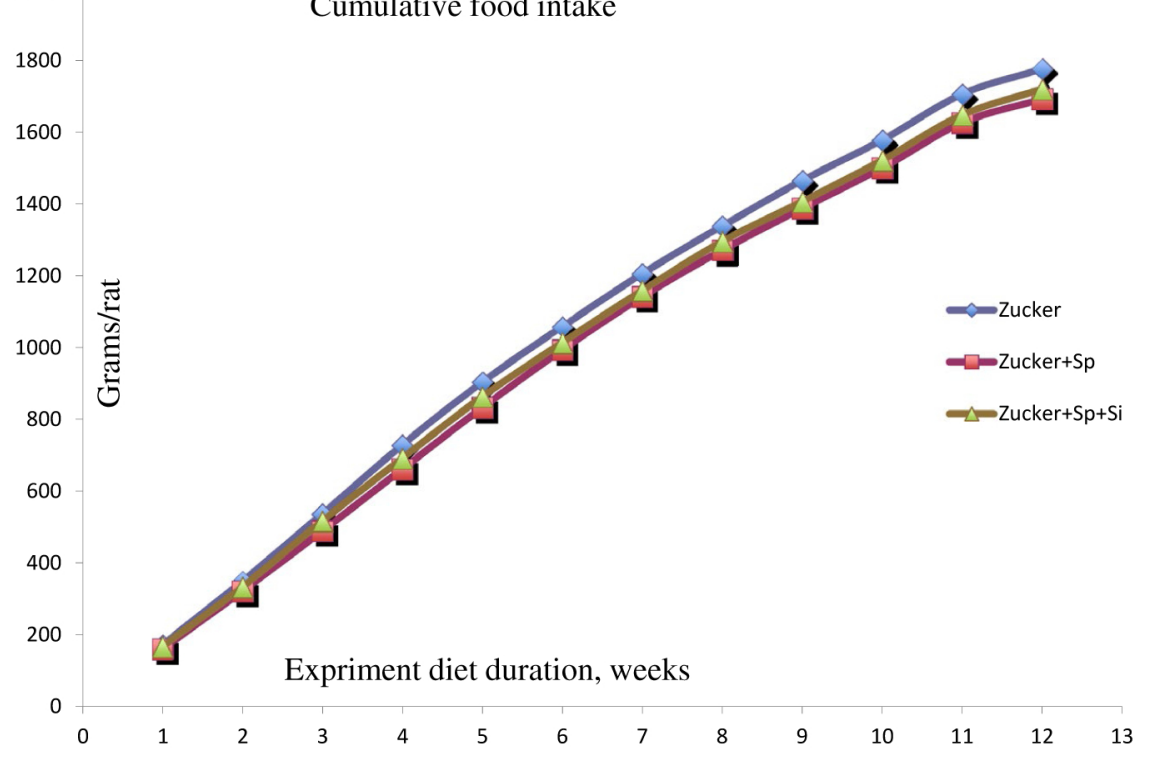

(b)

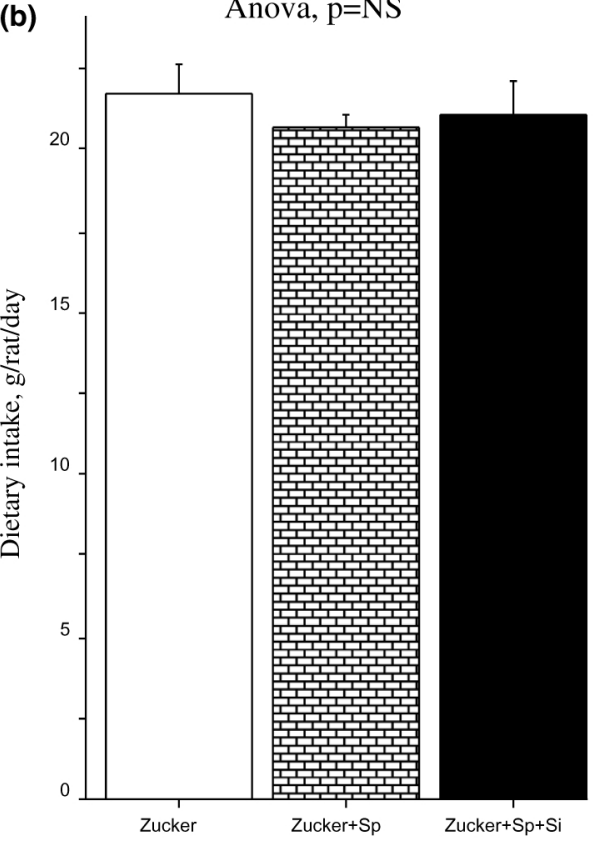

FIGURE 1 Time-course of rat food intake throughout the experiment. Note: Cumulative rat food intake during the whole study (a). mean rat food intake (b). Data are expressed as means $\pm S D(n=10)$. One-way ANOVA test, with Fischer test as a posttest, was performed to detect statistical significance among the three experimental groups. Statistical significance was set at an $\alpha$ level of $p<0.10$. Means with different letters differ. $\mathrm{Sp}$, spirulina supplement; $\mathrm{Sp}+\mathrm{Si}$, spirulina+silicon supplement 
(a) 500

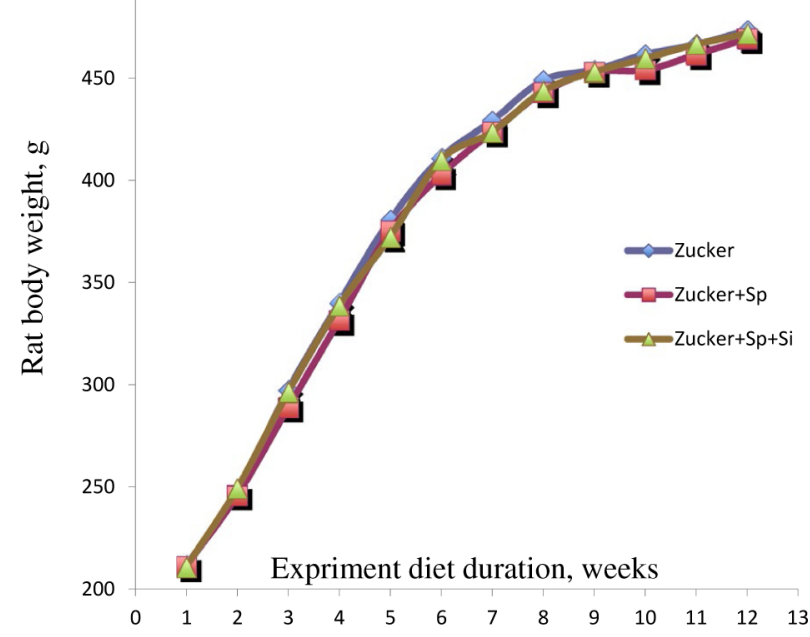

(b)

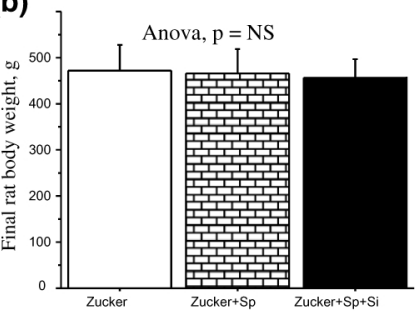

(d)

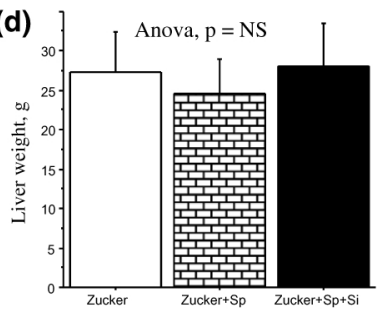

(c)

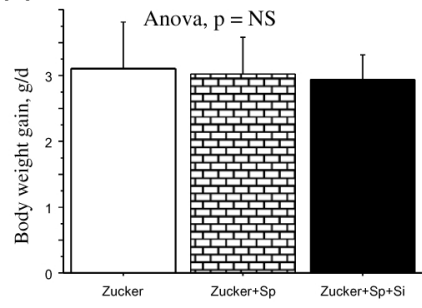

(e)

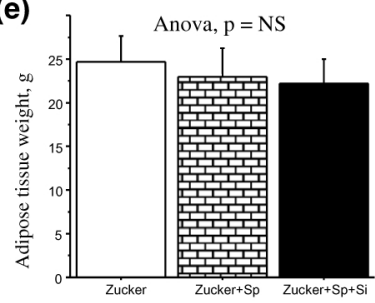

FIGURE 2 Time-course of rat body weight and rat characteristics throughout the experiment. Note: Time-course of rat body weight throughout the experiment (a). Mean rat body weight at the end of the study (b). Body weight gain (final weight-initial weight/number days of the study) (c). Rat liver weight (d). Adipose tissue weights (retroperitoneal+epididymal spots) (e). Data are expressed as means \pm SD $(n=10)$. One-way ANOVA test, with Fischer test as a posttest, was performed to detect statistical significance among the three experimental groups. Statistical significance was set at an $\alpha$ level of $p<0.10$. Means with different letters differ. Sp, spirulina supplement; $\mathrm{Sp}+\mathrm{Si}$, spirulina+silicon supplement

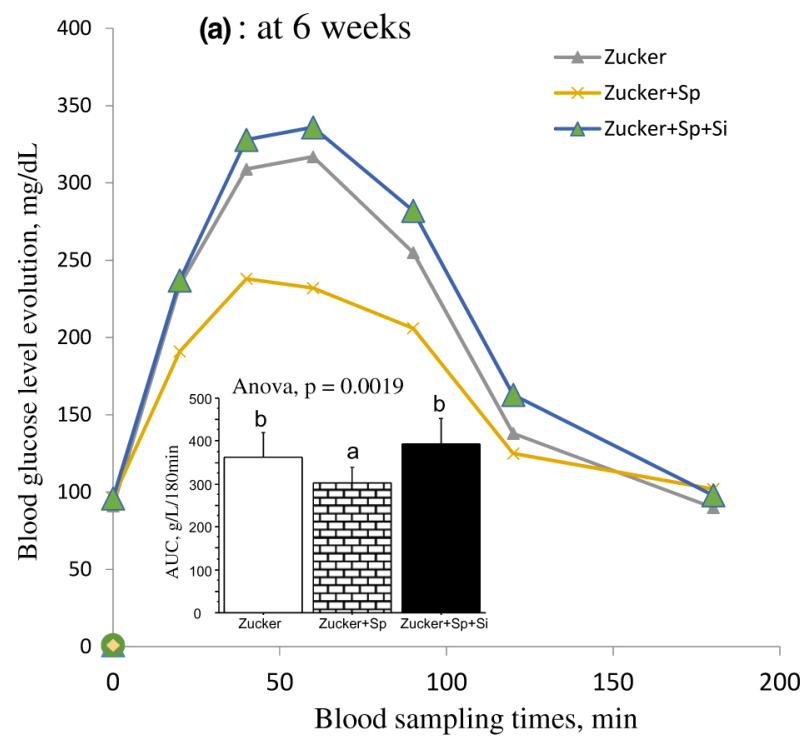

(b) : at 11 weeks

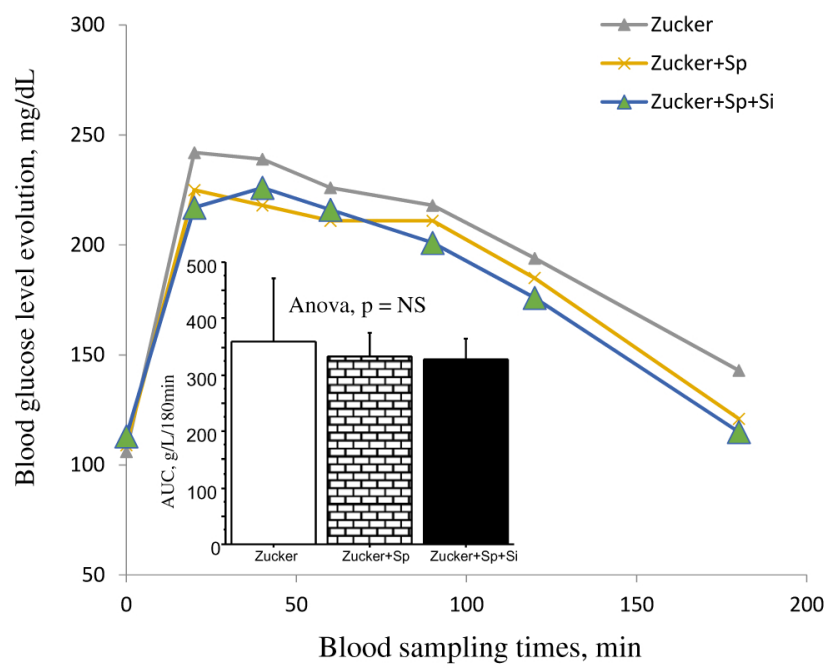

FIGURE 3 Oral glucose tolerance test on 6 and 11 weeks of diet intake. Note: Oral glucose tolerance test was performed on the 6 th week (a) and the 11th week (b) of diet. Rats received orally $2.5 \mathrm{~g}$ glucose/ $\mathrm{kg}$ b.w. and blood was sampled before and $20,40,6090,120$, and $180 \mathrm{~min}$ after glucose gavage. Data are expressed as means $\pm S D(n=10)$. One-way ANOVA test, with Fischer test as a posttest, was performed to detect statistical significance among the three experimental groups. Statistical significance was set at an $\alpha$ level of $p<0.10$. Means with different letters differ. Sp, spirulina supplement; Sp+Si, spirulina+silicon supplement

experimental groups (Supplemntary Table S3). In addition, the muscle gastrocnemus enzymatic activity of citrate synthase as well as that of the complexes I, II, II+III, and IV remained unchanged among the three experimental groups (Supplemntary Table S3). Finally, the enzymatic activity of liver and muscle mitochondrial $\beta-H A D$ remained also unchanged among the three experimental groups (Supplementary Table S3). So, both Sp and Sp+Si supplements were without effect on liver and muscle mitochondrial activity in the Zucker rats.

\section{5 | Blood inflammation and oxidative stress parameters}

The blood levels of the three major cytokines, TNF-a, IL-6, and MCP-1 and that of the CRP were assessed. The serum levels of these three cytokines and that of the CRP remained unchanged among the three experimental groups (Table 2).

Several long-established oxidative stress parameters were measured in blood and tissues. Among the blood oxidative stress 
TABLE 1 Blood glucose and lipid and hepatic lipid parameters in the Zucker rat

\begin{tabular}{|c|c|c|c|c|}
\hline Parameter & Zucker & Zucker+Sp & Zucker+Sp+Si & $p$ \\
\hline Plasma glucose, g/L & $2.20 \pm 0.74$ & $2.16 \pm 0.61$ & $2.31 \pm 0.77$ & NS \\
\hline Serum insulin, $\mu \mathrm{g} / \mathrm{L}$ & $17.3 \pm 1.6$ & $15.2 \pm 3.2$ & $16.8 \pm 2.7$ & NS \\
\hline HOMA-IR & $228 \pm 91$ & $185 \pm 69$ & $224 \pm 53$ & NS \\
\hline Serum leptin, $\mu \mathrm{g} / \mathrm{L}$ & $108 \pm 49$ & $114 \pm 49$ & $97 \pm 29$ & NS \\
\hline $\begin{array}{l}\text { Serum adiponectin, } \\
\mathrm{mg} / \mathrm{L}\end{array}$ & $9.56 \pm 1.67$ & $9.93 \pm 3.17$ & $9.59 \pm 2.21$ & NS \\
\hline $\begin{array}{l}\text { Serum triglycerides, } \\
\mathrm{mM}\end{array}$ & $4.34 \pm 1.62 a$ & $6.31 \pm 2.09 b$ & $4.47 \pm 2.09 a$ & 0.0753 \\
\hline $\begin{array}{l}\text { Serum free fatty } \\
\text { acids, mM }\end{array}$ & $1.98 \pm 1.03$ & $3.22 \pm 1.62$ & $2.58 \pm 0.56$ & NS \\
\hline $\begin{array}{l}\text { Serum total choles- } \\
\text { terol, mM }\end{array}$ & $3.55 \pm 0.36$ & $3.68 \pm 1.06$ & $4.07 \pm 0.82$ & NS \\
\hline $\begin{array}{l}\text { Serum paraoxonase } \\
\text { activity, U/L }\end{array}$ & $394 \pm 126$ & $324 \pm 151$ & $394 \pm 143$ & NS \\
\hline Serum ALAT, U/L & $69.8 \pm 19.6$ & $88.2 \pm 44.7$ & $67.3 \pm 19.4$ & NS \\
\hline $\begin{array}{l}\text { Liver triglycerides, } \\
\mathrm{mg} / \mathrm{g} \text { ww }\end{array}$ & $83.8 \pm 27.1$ & $77.2 \pm 32.0$ & $86.7 \pm 17.0$ & NS \\
\hline $\begin{array}{l}\text { Liver free fatty acids, } \\
\mathrm{mg} / \mathrm{g} \text { ww }\end{array}$ & $3.71 \pm 0.65$ & $3.74 \pm 0.48$ & $3.34 \pm 0.54$ & NS \\
\hline $\begin{array}{l}\text { Liver total choles- } \\
\text { terol, mg/g ww }\end{array}$ & $7.31 \pm 1.24$ & $6.92 \pm 1.12$ & $7.27 \pm 0.97$ & NS \\
\hline
\end{tabular}

Note: Data are expressed as means $\pm S D(n=10)$. One-way ANOVA test, with Fischer test as a posttest, was performed to detect statistical significance among the four experimental groups. Statistical significance was set at an $\alpha$ level of $p<0.10$. Means in a row with different letters differ. HOMA-IR, Homeostasis Model Assessment-Insulin Resistance; ALAT, alanine transaminase; Sp, spirulina; $\mathrm{Si}$, silicon. parameters, GssG levels were significantly increased with both the $\mathrm{Sp}$ and Sp+Si supplements (Table 2). All the other oxidative and antioxidative parameters measured in this study, namely TBARS, FRAP, sulfhydryl groups, and total GSH as well as SOD, and GPx activities remained unchanged among the three experimental groups (Table 2).

\section{6 | Liver and muscle oxidative stress parameters}

The effects of Sp and Sp+Si supplements on hepatic oxidative stress parameters were nearly similar to those observed on blood oxidative stress parameters. Only the liver NADPH oxidase-dependent $\mathrm{O}_{2}^{-}$production was significantly decreased with the Sp but not with the Sp+Si supplement (Table 3). However, this decrease was not accompanied by any major alteration in neither oxidative nor antioxidative parameters. Indeed, hepatic levels of TBARS, sulfhydryl groups, GSH, GssG, as well as the hepatic enzymatic activity of SOD, catalase, GPx and aconitase remained unchanged. So, both Sp and $\mathrm{Sp}+\mathrm{Si}$ supplements remained without any effect on these parameters (Table 3).

The effects of Sp and Sp+Si supplements on muscle oxidative stress parameters were also investigated. As shown in the supplementary Table S4, all the measured parameters, namely TBARS, sulfhydryl groups, and GSH as well as SOD, catalase and GPx activities remained unchanged among the three experimental groups.

\subsection{Gene expression of lipid metabolism, mitochondrial activity, inflammation, and redox status}

We studied hepatic expression of genes playing a key role in lipid metabolism, including Fat/CD36, Srebp-1c, Cpt-1, and Fasn. As shown in Table S4, the hepatic expression of all these genes remained similar among the Zucker group and the Zucker+Sp and Zucker+Sp+Si groups.

The gene expression of Glut2, Gck, and Pck1, controlling glucose metabolism, were investigated. While the gene expression of Glut2 and Gck remained unchanged, that of Pck1 increased with Sp suppelment but returned to the Zucker control value under the Si-enriched Sp (Table 4). Regarding mitochondrial activity, the gene expression of Pgc-1a and NRF1 remained unchanged, whereas that of Tfam increased with Sp suppelment and returned to the Zucker control value with the Si-enriched Sp. Finally, the hepatic gene expression of Rela, Tnf-a, Nrf2, and Hmox1, controlling inflammation and redox status, remained unchanged compared to the Zucker group. However, Sienriched Sp decreased significantly the gene expression of Hmox1, in comparsion to the Zucker+Sp group (Table 4). 
(a)

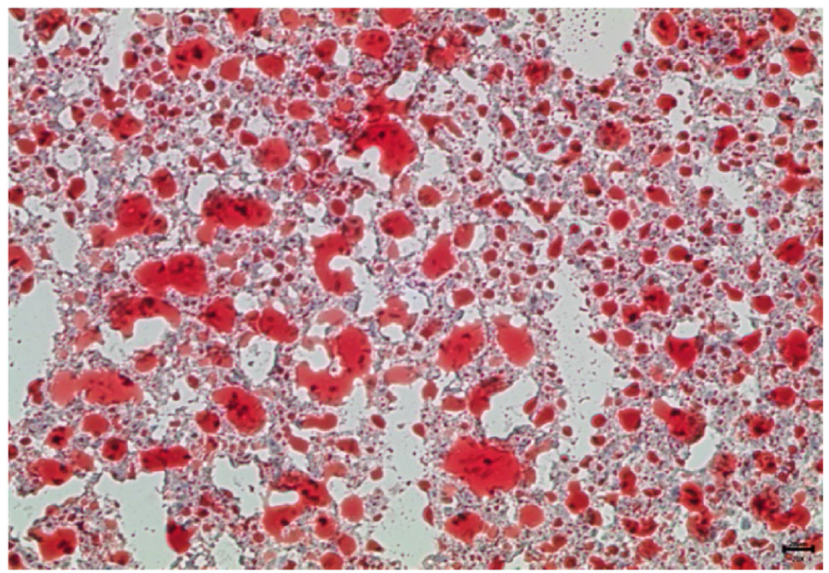

(c)

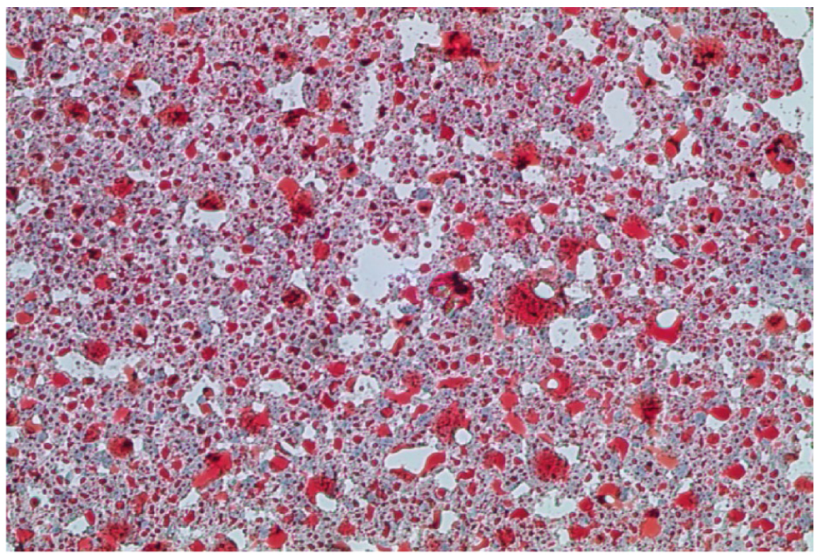

(b)

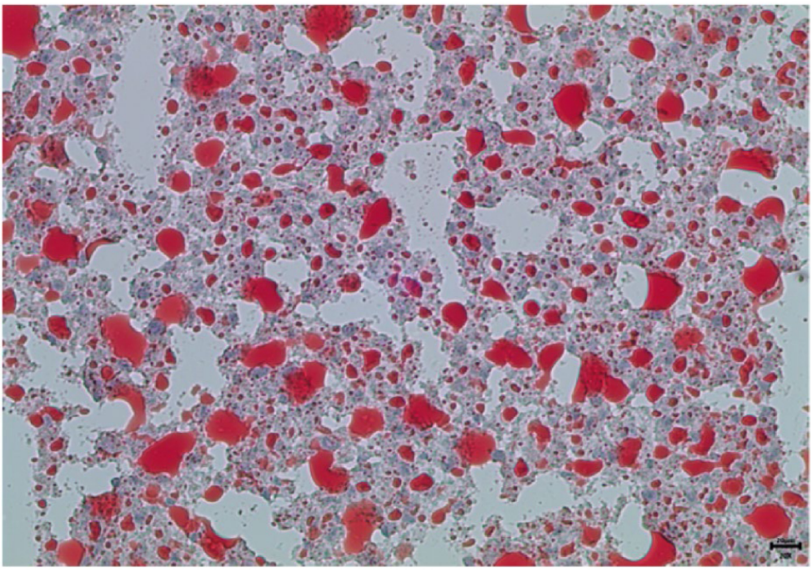

(d)

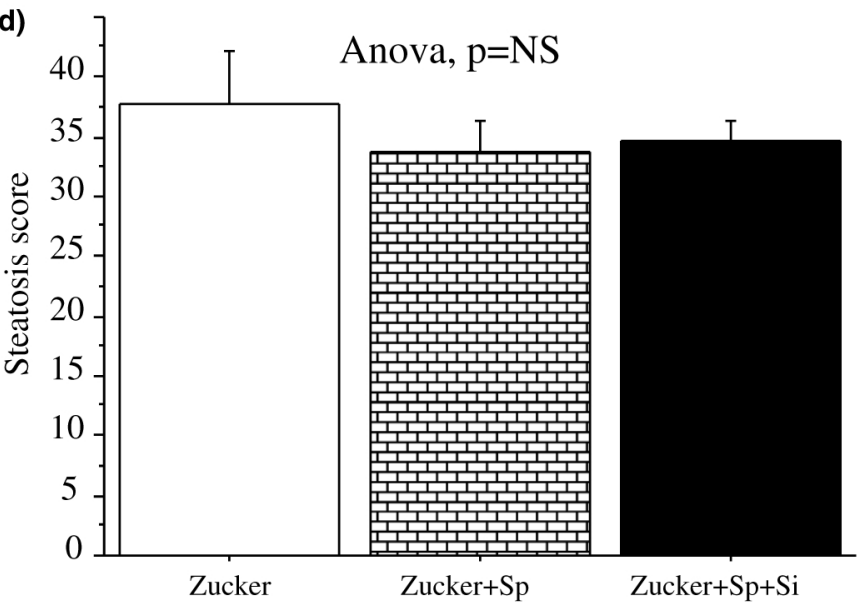

FIG URE 4 Oil Red O staining observation of rat liver tissue and hepatic steatosis score. Note: Histologic evaluation of hepatic steatosis in Zucker (a), Zucker+Sp (b) and Zucker+Sp+Si (c) rat groups. Illustrated images represent liver sections (400 magnification). To determine the hepatic steatosis score, at least 10 fields were scored and averaged for each liver sample (d). Data are expressed as means $\pm S D(n=3-4)$. One-way ANOVA test, with Fischer test as a posttest, was performed to detect statistical significance among the three experimental groups. Statistical significance was set at an $\alpha$ level of $p<0.10$. Means with different letters differ. Sp, spirulina supplement; Sp+Si, spirulina+silicon supplement

\section{4}

\section{DISCUSSION}

The present work was designed to determine the potential effects of $\mathrm{Sp}$ and $\mathrm{Sp}+\mathrm{Si}$ supplements on the major metabolic syndrome features, namely glucose intolerance and hepatic steatosis and their associated metabolic alterations, specifically inflammation, oxidative stress, and mitochondrial dysfunction, in a large chronic study of 12 weeks, in Zucker fatty rat. We have fixed these both doses of $\mathrm{Sp}$ and $\mathrm{Si}$ in a prelimiary study (Vidé, Romain, et al., 2015). The daily dose of Sp we supplied in the present study was $28.5 \mathrm{mg} / \mathrm{kg}$, which represents $2 \mathrm{~g}$ of Sp/day for un adulte of $70 \mathrm{~kg}$. A wide range of spirulina supplements in human studies has been reported. This varied from $1 \mathrm{~g} /$ day (Mazokopakis, Starakis, Papadomanolaki, Mavroeidi, \& Ganotakis, 2014), up to $10 \mathrm{~g} /$ day (Ngo-Matip et al., 2014) with various physiopathological states and different durations of administration. The daily dose of Si supplied in the present study was $0.57 \mathrm{mg} / \mathrm{kg}$, which represents $40 \mathrm{mg}$ of Si for un adulte of $70 \mathrm{~kg}$ which could considered as nutritional supplementation. Si supplementation studies, available in humans and animals, are generally in connection with bone metabolism, where high amounts of $\mathrm{Si}$ were often administered, and considered as pharmacological supplementations. Belles, Albina, Sanchez, and Domingo (1999) have administered Si to pregnant mice in drinking water at 118 and $236 \mathrm{mg} \mathrm{Si} / \mathrm{I}$ which correspond to about 0.5 and $1 \mathrm{mg} \mathrm{Si} / \mathrm{kg}$ b.w. In a rat study, soluble Si was given daily in water at the dose $20 \mathrm{mg} / \mathrm{kg}$ body weight/day (Qi \& Zheng, 2017). In another rat study, a high dose, $250 \mathrm{mg} \mathrm{Si} / \mathrm{kg}$ diet, and a very high dose $750 \mathrm{mg} \mathrm{Si} / \mathrm{kg}$ diet were tested in ovariectomized rats under calcium-replete condition ( $\mathrm{Bu}, \mathrm{Kim}, \&$ Choi, 2016). In a mouse study, Si was administered orally in the drinking water as a form of sodium metasilicate at different doses $(250,500$, and $750 \mathrm{mg} / \mathrm{L}$ ) for 4 weeks (Kim, Kim, Jung, \& Choi, 2014).

It is well known that Zucker fatty rats presented obesity, insulin resistance, hyperlipidemia, and high liver weight associated with overt steatosis (Saito et al., 2018). These characteristics and metabolic alterations are generally reported to be associated with high free radical production and oxidative stress onset (Raza, John, \& Howarth, 2015). Our results indicate that $\mathrm{Sp}$, but not $\mathrm{Sp}+\mathrm{Si}$ supplement, has shown some moderate effects on rat characteristics and blood/hepatic metabolic parameters. Globally, Sp supplement increased serum TG level, 
TABLE 2 Blood inflammation and oxidative stress and antioxidant status in the Zucker rat

\begin{tabular}{|c|c|c|c|c|}
\hline Parameter & Zucker & Zucker+Sp & Zucker+Sp+Si & $p$ \\
\hline \multicolumn{5}{|l|}{$\begin{array}{l}\text { Inflammation } \\
\text { parameters }\end{array}$} \\
\hline Serum TNF $\alpha, \mathrm{ng} / \mathrm{L}$ & $13.4 \pm 1.5$ & $12.7 \pm 1.6$ & $13.6 \pm 1.7$ & NS \\
\hline Serum IL-6, ng/L & $15.7 \pm 6.1$ & $13.8 \pm 6.3$ & $12.4 \pm 3.2$ & NS \\
\hline MCP-1, $\mu \mathrm{g} / \mathrm{L}$ & $38.8 \pm 16.8$ & $36.9 \pm 15.0$ & $37.2 \pm 8.2$ & NS \\
\hline CRP, mg/L & $455 \pm 107$ & $412 \pm 130$ & $438 \pm 115$ & NS \\
\hline \multicolumn{5}{|l|}{$\begin{array}{l}\text { Oxidative stress and } \\
\text { antioxidant status }\end{array}$} \\
\hline Plasma TBARS, $\mu \mathrm{M}$ & $12.4 \pm 1.6$ & $13.6 \pm 2.0$ & $13.1 \pm 2.1$ & NS \\
\hline $\begin{array}{l}\text { Plasma FRAP, } \mu \mathrm{M} \mathrm{Eq} \\
\mathrm{Fe}^{+2} / \mathrm{L}\end{array}$ & $10.8 \pm 4.1$ & $15.2 \pm 6.9$ & $13.3 \pm 9.2$ & NS \\
\hline Plasma SH Gp, mM & $0.47 \pm 0.07$ & $0.54 \pm 0.07$ & $0.53 \pm 0.12$ & NS \\
\hline Blood GSH, $\mu \mathrm{M}$ & $701 \pm 62$ & $694 \pm 63$ & $707 \pm 141$ & NS \\
\hline Blood GssG, $\mu \mathrm{M}$ & $3.97 \pm 4.04 a$ & $10.67 \pm 5.54 b$ & $8.79 \pm 4.22 b$ & 0.0146 \\
\hline Blood GssG/GSH & $1.08 \pm 1.00 \mathrm{a}$ & $3.04 \pm 1.61 b$ & $2.52 \pm 1.20 b$ & 0.0095 \\
\hline $\mathrm{RBC}$ catalase, $\mathrm{KU} / \mathrm{mL}$ & $77.7 \pm 4.6$ & $75.7 \pm 3.4$ & $74.7 \pm 5.0$ & NS \\
\hline Plasma SOD, U/L & $31.5 \pm 3.0$ & $32.6 \pm 4.6$ & $30.0 \pm 3.1$ & NS \\
\hline Plasma GPx, U/L & $28.5 \pm 2.8$ & $28.6 \pm 6.6$ & $30.1 \pm 4.4$ & NS \\
\hline
\end{tabular}

Note: Data are expressed as means $\pm S D(n=10)$. One-way ANOVA test, with Fischer test as a posttest, was performed to detect statistical significance among the four experimental groups. Statistical significance was set at an $\alpha$ level of $p<0.10$. Means in a row with different letters differ. TNF- $\alpha$, tumor necrosis factor- $\alpha$; IL-6, interleukine 6; MCP-1, Monocyte chemoattractant protein 1 ; CRP, C-reactive protein; TBARS, thiobarbituric acid reactive substances; FRAP, ferric reducing antioxidant power; SH Gp, sulfhydryl groups; GSH, glutathione; GssG, oxidized glutathione; RBC, red blood cells; SOD, superoxide dismutase; GPx, glutathione peroxidase; Sp, spirulina; Si, silicon.

\begin{tabular}{|c|c|c|c|c|}
\hline Parameter & Zucker & Zucker+Sp & Zucker+Sp+Si & $p$ \\
\hline NADPH oxidase, $A U$ & $15.5 \pm 3.6 a$ & $12.3 \pm 3.6 b$ & $15.0 \pm 2.6 a$ & 0.0803 \\
\hline TBARS, nmol/g ww & $87.3 \pm 18.7$ & $98.5 \pm 13.9$ & $89.4 \pm 17.4$ & NS \\
\hline $\begin{array}{l}\text {-SH Gp, nmol/mg } \\
\text { protein }\end{array}$ & $182 \pm 24$ & $169 \pm 40$ & $178 \pm 27$ & NS \\
\hline $\mathrm{GSH}, \mathrm{nmol} / \mathrm{g}$ ww & $2,540 \pm 356$ & $2,332 \pm 619$ & $2,363 \pm 311$ & NS \\
\hline GssG, nmol/g ww & $27.1 \pm 11.3$ & $21.5 \pm 10.7$ & $19.9 \pm 6.4$ & NS \\
\hline$($ GssG/GSH) × 100 & $1.06 \pm 0.39$ & $0.89 \pm 0.23$ & $0.85 \pm 0.31$ & NS \\
\hline SOD, U/mg protein & $39.3 \pm 6.3$ & $38.2 \pm 2.6$ & $37.3 \pm 3.3$ & NS \\
\hline $\begin{array}{l}\text { Catalase, U/mg } \\
\text { protein }\end{array}$ & $1,185 \pm 103$ & $1,133 \pm 102$ & $1,191 \pm 73$ & NS \\
\hline $\mathrm{GPx}, \mathrm{mU} / \mathrm{mg}$ protein & $6,168 \pm 1,255$ & $6,652 \pm 527$ & $6,334 \pm 762$ & NS \\
\hline $\begin{array}{l}\text { Aconitase, } \mathrm{mU} / \mathrm{mg} \\
\text { protein }\end{array}$ & $31.6 \pm 9.5$ & $33.8 \pm 6.8$ & $34.0 \pm 9.9$ & NS \\
\hline
\end{tabular}

TAB LE 3 Liver oxidative stress and antioxidant status in the Zucker rat 
TABLE 4 Gene expression of key regulators of lipid and glucose metabolism, inflammation and redox status and mitochondrial biogenesis and activity in the Zucker rat liver

\begin{tabular}{llccc} 
Parameter & Zucker & Zucker+Sp & Zucker+Sp+Si & $p$ \\
\hline Lipid metabolism & & & & \\
FAT/CD36 & $100 \pm 61$ & $117 \pm 38$ & $85 \pm 28$ & NS \\
Srebf1c & $100 \pm 23$ & $95 \pm 31$ & $81 \pm 24$ & NS \\
Cpt-1 & $100 \pm 37$ & $109 \pm 41$ & $89 \pm 29$ & NS \\
Fasn & $100 \pm 32$ & $116 \pm 48$ & $101 \pm 40$ & NS \\
Glucose metabolism & & & & \\
Glut2 & $100 \pm 32$ & $132 \pm 48$ & $95 \pm 42$ & NS \\
Gck & $100 \pm 80$ & $65 \pm 49$ & $97 \pm 58$ & NS \\
Pck-1 & $100 \pm 19 \mathrm{a}$ & $128 \pm 41 \mathrm{~b}$ & $95 \pm 32 \mathrm{a}$ & $\mathbf{0 . 0 6 7 1}$ \\
Inflammation and redox & & & & \\
$\quad$ status & & & & \\
NF-kB & $100 \pm 42$ & $103 \pm 34$ & $82 \pm 28$ & NS \\
TNF $\alpha$ & $100 \pm 27$ & $107 \pm 36$ & $91 \pm 18$ & NS \\
Nfe2l2 & $100 \pm 32$ & $115 \pm 35$ & $96 \pm 32$ & NS \\
Hmox-1 & $100 \pm 36 \mathrm{ab}$ & $115 \pm 42 \mathrm{~b}$ & $74 \pm 27 \mathrm{a}$ & $\mathbf{0 . 0 6 1 9}$ \\
Mitochondrial biogen- & & & & \\
esis \& activity & & $142 \pm 86$ & $81 \pm 27$ & NS \\
Pgc-1 $\alpha$ & $100 \pm 40$ & $145 \pm 50 \mathrm{~b}$ & $105 \pm 30 \mathrm{a}$ & $\mathbf{0 . 0 2 1 6}$ \\
Tfam & $100 \pm 18 \mathrm{a}$ & $120 \pm 29$ & $100 \pm 25$ & NS \\
NRF-1 & $100 \pm 19$ & & & \\
\hline
\end{tabular}

Note: Data are expressed as means $\pm S D(n=10)$. One-way ANOVA test, with Fischer test as a posttest, was performed to detect statistical significance among the four experimental groups. Statistical significance was set at an $\alpha$ level of $p<0.10$. Means in a row with different letters differ. Fat/Cd36, Fatty acid translocase; Srebf1c (Srebp-1c), Sterol regulatory element binding transcription factor-1c; Cpt-1, Carnitine palmitoyltransferase I; Fasn, Fatty acid synthase; Glut2, glucose transporter 2; Gck, Glucokinase; Pck1, Phosphoenolpyruvate carboxykinase 1; NF-kB (Rela p65), Nuclear factor-kappa B (Rela = p65); Tnfa, Tumor Necrosis Factor a; Nfe2l2 (Nrf2), Nuclear factor erythroid-2-related factor-2; Hmox1, Heme oxygenase-1; Pgc-1 $\alpha$ (Ppargc-1 $\alpha$ ), Peroxisome proliferator-activated receptor gamma coactivator-1a; Tfam, Mitochondrial transcription factor A; NRF1, Nuclear respiratory factor 1; Ppia (CypA), Cyclophiline A. Sp, spirulina; Si, silicon. decreased hepatic NADPH oxidase activity and ameliorated glucose tolerance at the 6th but not at the 11th week of diet, associated with some hepatic gene expression alterations. However, $\mathrm{Sp}+\mathrm{Si}$ supplement does not appear to have any major beneficial/adverse effect, except an increase in blood GssG levels in the Zucker fatty rat in the experimental conditions of this study.

One of the major metabolic characteristics of Zucker fatty rat is glucose intolerance and insulin resistance. As already reported, Zucker fatty rat exhibited high plasma levels of glucose and insulin and HOMA-IR index, however, both $\mathrm{Sp}$ and $\mathrm{Sp}+\mathrm{Si}$ supplements did not show any effect of these parameters. Based on the glucose tolerence test, the Sp supplement, but not with Sp+Si supplement, ameliorated significantly glucose tolerance at the sixth week but not at the end of the experiment. It is possible that the disappearance of this effect toward the 11 weeks may be due to a biological adaptation process. However, this 6-week effect of Sp remains a good result. In obesogenic diet-fed rats (Vide et al., 2018), we have reported that both $\mathrm{Sp}$ and $\mathrm{Sp}+\mathrm{Si}$ supplements significantly reduced glucose intolerance that were observed at both 6th and 11th week of the diet. The effects of $S p$ and $S p+S i$ supplements were thus different between Zucker fatty rat and obesogenic diet-fed rats. Rare are the studies concerning Sp effect on glucose intolerance in Zucker or in obesogenic diet-fed rats. In a recent study, Vidé, Virsolvy, et al. (2015) have fed syrian hamsters for 12 weeks with an atherogenic diet containing 10\% hydrogenated coconut oil and $2 \mathrm{~g} / \mathrm{kg}$ cholesterol. They reported that Sp intake decreased blood insulin level, whereas blood glucose remained unchanged. In diabetec rats, Moura et al. (2011) have reported that Sp supplementation was not able to improve serum glucose homeostasis in diabetic rats. In addition, Ou, Lin, Pan, Yang, and Cheng (2012) have investigated the preventive effect of Sp on alloxan-injured mice. They reported that Sp ameliorates alloxan-induced diabetes mellitus by activating insulin signaling pathway and glucokinase expression in pancreas and liver in diabetic mice. Finally, Simon, Baskaran, Shallauddin, Ramalingam, and Evan Prince (2018) have shown that Sp possesses significant antidiabetic and antihyperlipidemic effects in streptozotocin-induced diabetic rats by effectively reducing the rise in blood glucose levels and lipid profile.

Another major characteristic of Zucker fatty rats is dyslipidemia with liver fat accumulation and hepatic steatosis. Indeed, Zucker 
fatty rat exhibited high plasma levels of cholesterol, TG and FFA. Only Sp but not Sp+Si supplement increased significantly and nonsignificantly plasma TG and FFA levels, respectively. In this study, the 12-week Sp and Sp+Si supplementation showed no major effects on liver fat accumulation and hepatic steatosis. Indeed, liver contents of cholesterol, TG and FFA as well as plasma ALAT activity remained unchanged in the three experimental groups. Similar results have been obtained by our group when $\mathrm{Sp}$ and $\mathrm{Sp}+\mathrm{Si}$ supplements were tested in obesogenic diet-fed rats (Vide et al., 2018). This is also in agreement with our previous study performed on Syrian hamsters, where we reported that supplementation with Sp, enriched or not, provided no protection against liver steatosis (Vidé, Virsolvy, et al., 2015). However, Yigit et al. (2016) have reported that Sp supplementation reduced serum cholesterol and triglyceride levels in rats fed a high-fat diet to near control levels, with a decrease in the apoptotic index in the groups fed a high fat or a basic diet when supplemented with Sp. In addition, Moura et al. (2011) showed that Sp supplementation was effective in reducing total circulating levels of LDL-cholesterol as well as hepatic lipids contents. In a recent study, Yousefi, Mottaghi, and Saidpour (2018) have shown that SP, as a complementary therapy may have beneficial effects on management of weight loss and also reduction in TG levels through possible modulatory effects on anti-inflammatory pathways. Finally, Pak et al. (2012) have reported that $\mathrm{Sp}$ administration to a $\mathrm{NASH}$ rat model might lessen the inflammatory response through antioxidative and anti-inflammatory mechanisms, breaking the crosstalk between oxidative stress and inflammation, and effectively inhibited NASH progression.

Liver mitochondria play a fundamental role in the development, perpetuation and worsening of glucose intolerance and hepatic steatosis. Since mitochondria are the main producers of both cellular energy and free radicals, dysfunctional mitochondria may play a key role in the development of insulin resistance and ectopic fat storage in the liver, thus supporting the emerging idea that mitochondrial dysfunction is closely related to the development of obesity, NAFLD and type-2 diabetes mellitus (Pessayre, 2007). The results of the current study have shown that neither $\mathrm{Sp}$ nor $\mathrm{Sp}+\mathrm{Si}$ has any effect on hepatic or muscle mitochondrial function compared to the Zucker rat without supplementation. In addition, the enzymatic activity of $\beta$-HAD, a major key in the mitochondrial fatty acid oxidation, also remained unchanged in both liver and muscle under $\mathrm{Sp}$ or Si-enriched Sp. Although some studies have suggested possible mitochondrial dysfunction in obese Zucker rats, many others have failed to observe such a dysfunction. Brady and Hoppel (1983) have studied the hepatic mitochondrial function in lean and obese Zucker rats in the fed state and at 3 and 6 days of starvation. Their results indicated that mitochondrial capacity to oxidize fatty acids and to produce keto acids was not affected by genetic obesity. Another study has reported no role for mitochondrial dysfunction in fatty liver and insulin resistance in obese Zucker rats (Flamment et al., 2008). Indeed, they have showed that isolated liver mitochondria from lean and obese insulin-resistant Zucker rats had strictly the same mitochondrial function. If mitochondrial function was not altered in the Zucker fatty rat tissues, this may explain why Sp or Sp+Si supplements had no major effect on hepatic and muscle mitochondrial function in this study.

The critical roles of cellular ROS and oxidative stress involved in the pathogenesis of liver diseases have been highlighted for decades, and accumulating evidence showed that a vicious cycle could be created by oxidative stress and inflammation. Oxidative stress could elevate proinflammatory gene expression by signaling pathways such as NF- $\kappa$ B, while infiltrated inflammatory cells and cytokines like IL-6 could produce more oxidative stress (Tariq, Green, \& Hodson, 2014). We have investigated in this study one of the major sources of hepatic ROS production; namely NADPH oxidase, which is also an essential component of redox signaling mechanisms. Indeed, abnormal activation of NADPH oxidase can lead to overproduction of superoxide anions, which are linked to oxidative stress-induced tissue injury. In the present study, liver NADPH oxidase dependent-superoxide anion production was markedly decreased with the Sp supplement but not with the $\mathrm{Sp}+\mathrm{Si}$ supplement compared to the Zucker rats. Otherwise, several long-established oxidative and antioxidative biomarkers have been performed to assess in vivo oxidative stress in blood, liver, and muscle. Among the blood oxidative stress markers, only oxidized glutathione levels and GssG/GSH ratio were decreased with both Sp and $\mathrm{Sp}+\mathrm{Si}$ supplements compared to the Zucker rats, although enzymatic activity of plasma GPx remained unchanged. All the other measured oxidative stress markers in blood, liver, and muscle remained unchanged. This may mean that the decrease in NADPH oxidase activity was modest to alter the tissue oxidative stress markers. In the context of this study, the $\mathrm{Sp}$ and $\mathrm{Sp}+\mathrm{Si}$ supplements did not exhibit any major effect on these plasma or liver or muscle oxidative stress markers.

Although we observed few significant biological effects of Sp or $\mathrm{Sp}+\mathrm{Si}$ supplements in Zucker rats in this study, we investigated at the molecular level whether these supplements may have effects on lipid and glucose metabolism, as well as on mitochondrial activity and redox status, by determining the liver gene expression of key actors controlling these metabolic pathways. The hepatic expression of the four genes involved in the lipid metabolism, namely Fat/CD36, Srebp1c, Cpt1, and Fasn, was not affected by Sp or Sp+Si supplements compared to the Zucker rats. This is in agreement with the biological results where liver lipid content was not affected neither by $\mathrm{Sp}$ nor by $\mathrm{Sp}+\mathrm{Si}$ supplements. Regarding glucose metabolism, the gene expression of Glut2 and Gck remained unchanged, whereas that of Pck1 was increased with the Sp supplement but not with the $\mathrm{Sp}+\mathrm{Si}$ supplement compared to the Zucker rats. It is questionable whether there is a possible association between the increased expression of this gluconeogenic gene and the reduced intolerance to glucose at 6 weeks of diet under the Sp supplementation.

Regarding mitochondrial activity, Sp supplement increased the hepatic gene expression of the mitochondrial transcription factor A, Tfam, that plays a key role for the regulation of mtDNA replication, and therefore, for the mitochondrial biogenesis. However, this increase was not translated into higher mitochondrial activity in this group, probably because the gene expression of the transcription factors Pgc-1 $\alpha$ and NRF1, playing a central role in a regulatory network governing the transcriptional control of mitochondrial biogenesis and 
respiratory function, remained unchanged. Finally, the inflammation and the redox status were investigated by measuring the liver gene expression of NF-kB (p65), $\operatorname{Tnf} \alpha, \mathrm{Nrf2}$, and Hmox1. Only the gene expression of Hmox1 was increased with the Sp supplement but not with the $\mathrm{Sp}+\mathrm{Si}$ supplement compared to the Zucke rats, whereas the hepatic expression of the three other genes remained unchanged. We may speculate that the decrease in the NADPH oxidase activity may be responsible for the higher gene expression of Hmox1 observed under the Sp supplement in this diabetic animal model. Indeed, heme oxygenases have important biological functions in vascular homeostasis and NADPH oxidase has been implicated in the development of hypertension and hypertension-related organ injuries. Indeed, it has been recently reported that heme oxygenase-1 can modulate production of reactive oxygen species, both in vivo and in vitro, from NADPH oxidase, a major enzymatic source of reactive oxygen species generation in the vascular wall (Chan, Dusting, Liu, \& Jiang, 2014).

In conclusion, it is well known that Zucker fatty rats exhibited glucose intolerance, high hepatic lipid accumulation and overt steatosis with supposed mitochondrial dysfunction and oxidative stress. In the present study, the $\mathrm{Sp}$ and $\mathrm{Sp}+\mathrm{Si}$ supplements showed very limited effects on rat characteristics and on blood, hepatic, and muscle metabolic parameters in this animal model. Indeed, the dietary intake of Sp supplement but not Sp+Si supplement mainly improved transitorily glucose tolerance and decreased the enzymatic activity of hepatic NADPH oxidase. Overall, Si supplementation of spirulina does not appear to have more beneficial/adverse effects than spirulina alone. Other experiments with different species of rats/mice, different diets, or different durations of diet intake should be undertaken to confirm or invalidate these results.

\section{ACKNOWLEDGMENTS}

The present results are part of the Spirulicium Cardio project, co-funded by the Occitanie region (France) and by the European Regional Development Fund. The authors wish to thank the Occitanie region and the European Regional Development Fund for their valuable support. The authors are deeply grateful for Drs Jean-Max Rouanet and Jean-Claude Baccou (scientific advisors to Phyco-Biotech) and Mr Gilbert Gay (President of Phyco-Biotech) for their major support and contribution to prepare and conclude this project. The authors wish also to thank the animal staff from METAMUS DMEM facility, which belongs to Montpellier animal facilities (RAM, BIOCAMPUS).

\section{CONFLICT OF INTEREST}

The authors confirm that this article content has no conflicts of interest.

\section{ETHICS STATEMENT}

Our institution guidelines for the care and use of laboratory animals were observed and that all experimental procedures were approved by the local ethical committee in Montpellier, France (Reference CEEA-LR-12002).

\section{AUTHOR CONTRIBUTIONS}

Author contributions were as follows: study design (CC, CF-C, NJ, and SG), data collection (JV, BB, BJ, and GF), statistical analysis (CC and $C F-C$ ), data interpretation (CC, CF-C, FC, and SG), manuscript preparation (CC, CF-C, and SG), literature search (CC and CF-C), and funds collection (CC, NJ, and SG).

\section{REFERENCES}

Aoun, M., Fouret, G., Michel, F., Bonafos, B., Ramos, J., Cristol, J.-P., ... Feillet-Coudray, C. (2012). Dietary fatty acids modulate liver mitochondrial cardiolipin content and its fatty acid composition in rats with non alcoholic fatty liver disease. Journal of Bioenergetics and Biomembranes, 44(4), 439-452. https://doi.org/10.1007/ s10863-012-9448-x

Beers, R., \& Sizer, I. (1952). A spectrophotometric method for measuring the breakdown of hydrogen peroxide by catalase. Journal of Biological Chemistry, 195(1), 133-140.

Belles, M., Albina, M. L., Sanchez, D. J., \& Domingo, J. L. (1999). Lack of protective effects of dietary silicon on aluminium-induced maternal and developmental toxicity in mice. Pharmacology and Toxicology, 85(1), 1-6. https://doi.org/10.1111/j.1600-0773.1999.tb01055.x

Brady, L. J., \& Hoppel, C. L. (1983). Hepatic mitochondrial function in lean and obese Zucker rats. American Journal of Physiology, 245(3), E239-E245. https://doi.org/10.1152/ajpendo.1983.245.3.E239

Bu, S. Y., Kim, M. H., \& Choi, M. K. (2016). Effect of Silicon supplementation on bone status in ovariectomized rats under calcium-replete condition. Biological Trace Element Research, 171(1), 138-144. https:// doi.org/10.1007/s12011-015-0506-1

Cases, J., Wysocka, I. A., Caporiccio, B., Jouy, N., Besancon, P., Szpunar, J., \& Rouanet, J. M. (2002). Assessment of selenium bioavailability from high-selenium spirulina subfractions in selenium-deficient rats. Journal of Agriculture and Food Chemistry, 50(13), 3867-3873. https:// doi.org/10.1021/jf011646t

Chan, E. C., Dusting, G. J., Liu, G. S., \& Jiang, F. (2014). Redox mechanisms of the beneficial effects of heme oxygenase in hypertension. Journal of Hypertension, 32(7), 1379-1387. discussion 1387. https:// doi.org/10.1097/HJH.0000000000000179

Chen, T., Wong, Y. S., \& Zheng, W. (2006). Purification and characterization of selenium-containing phycocyanin from selenium-enriched Spirulina platensis. Phytochemistry, 67(22), 2424-2430. https://doi. org/10.1016/j.phytochem.2006.08.004

Clayton, P. T., Eaton, S., Aynsley-Green, A., Edginton, M., Hussain, K., Krywawych, S., ... van den Berg, I. E. (2001). Hyperinsulinism in short-chain L-3-hydroxyacyl-CoA dehydrogenase deficiency reveals the importance of beta-oxidation in insulin secretion. The Journal of Clinical Investigation, 108(3), 457-465.

Djohan, Y. F., Badia, E., Bonafos, B., Fouret, G., Lauret, C., Dupuy, A.-M., ... Feillet-Coudray, C. (2018). High dietary intake of palm oils compromises glucose tolerance whereas high dietary intake of olive oil compromises liver lipid metabolism and integrity. European Journal of Nutrition, 1-17. https://doi.org/10.1007/s00394-018-1854-3 
Feillet-Coudray, C., Sutra, T., Fouret, G., Ramos, J., Wrutniak-Cabello, C., Cabello, G., ... Coudray, C. (2009). Oxidative stress in rats fed a high-fat high-sucrose diet and preventive effect of polyphenols: Involvement of mitochondrial and NAD(P)H oxidase systems. Free Radical Biology and Medicine, 46(5), 624-632. https://doi.org/10.1016/j.freeradbio med.2008.11.020

Flamment, M., Arvier, M., Gallois, Y., Simard, G., Malthiery, Y., Ritz, P., \& Ducluzeau, P. H. (2008). Fatty liver and insulin resistance in obese Zucker rats: No role for mitochondrial dysfunction. Biochimie, 90(9), 1407-1413. https://doi.org/10.1016/j.biochi.2008.05.003

Flohe, L., \& Gunzler, W. A. (1984). Assays of glutathione peroxidase. Methods in Enzymology, 105, 114-121.

Griffith, O. W. (1980). Determination of glutathione and glutathione disulfide using glutathione reductase and 2-vinylpyridine. Analytical Biochemistry, 106(1), 207-212. https://doi. org/10.1016/0003-2697(80)90139-6[pii]

Hosseini, S. M., Khosravi-Darani, K., \& Mozafari, M. R. (2013). Nutritional and medical applications of spirulina microalgae. Mini Reviews in Medicinal Chemistry, 13(8), 1231-1237.

Janssen, A. J., Trijbels, F. J., Sengers, R. C., Smeitink, J. A., van den Heuvel, L. P., Wintjes, L. T., ... Rodenburg, R. J. (2007). Spectrophotometric assay for complex $\mathrm{I}$ of the respiratory chain in tissue samples and cultured fibroblasts. Clinical Chemistry, 53(4), 729-734. https://doi. org/10.1373/clinchem.2006.078873

Jocelyn, P. C. (1987). Spectrophotometric assay of thiols. Methods in Enzymology, 143, 44-67.

Jugdaohsingh, R., Watson, A. I., Pedro, L. D., \& Powell, J. J. (2015). The decrease in silicon concentration of the connective tissues with age in rats is a marker of connective tissue turnover. Bone, 75, 40-48. https://doi.org/10.1016/j.bone.2015.02.004

Kim, M. H., Kim, E. J., Jung, J. Y., \& Choi, M. K. (2014). Effect of watersoluble silicon supplementation on bone status and balance of calcium and magnesium in male mice. Biological Trace Element Research, 158(2), 238-242. https://doi.org/10.1007/s12011-014-9936-4

Koníčková, R., Vaňková, K., Vaníková, J., Vánová, K., Muchová, L., Subhanová, I., ... Vítek, L. (2014). Anti-cancer effects of blue-green alga Spirulina platensis, a natural source of bilirubin-like tetrapyrrolic compounds. Annals of Hepatology, 13(2), 273-283. https://doi. org/10.1016/S1665-2681(19)30891-9

Loeper, J., Goy, J., Fragny, M., Troniou, R., \& Bedu, O. (1988). Study of fatty acids in atheroma induced in rabbits by an atherogenic diet with or without silicon i.v. treatment. Life Sciences, 42(21), 2105-2112.

Lupatini, A. L., Colla, L. M., Canan, C., \& Colla, E. (2017). Potential application of microalga Spirulina platensis as a protein source. Journal of the Science of Food and Agriculture, 97(3), 724-732. https://doi. org/10.1002/jsfa.7987

Maehira, F., Motomura, K., Ishimine, N., Miyagi, I., Eguchi, Y., \& Teruya, S. (2011). Soluble silica and coral sand suppress high blood pressure and improve the related aortic gene expressions in spontaneously hypertensive rats. Nutrition Research, 31(2), 147-156. https://doi. org/10.1016/j.nutres.2010.12.002

Marklund, S. (1976). Spectrophotometric study of spontaneous disproportionation of superoxide anion radical and sensitive direct assay for superoxide dismutase. Journal of Biological Chemistry, 251(23), 7504-7507.

Mazo, V. K., Gmoshinski, I. V., \& Zorin, S. N. (2007). New food sources of essential trace elements produced by biotechnology facilities. Biotechnology Journal, 2(10), 1297-1305. https://doi.org/10.1002/ biot. 200700015

Mazokopakis, E. E., Starakis, I. K., Papadomanolaki, M. G., Mavroeidi, N. G., \& Ganotakis, E. S. (2014). The hypolipidaemic effects of Spirulina (Arthrospira platensis) supplementation in a Cretan population: A prospective study. Journal of the Science of Food and Agriculture, 94(3), 432-437. https://doi.org/10.1002/jsfa.6261
Moura, L. P., Puga, G. M., Beck, W. R., Teixeira, I. P., Ghezzi, A. C., Silva, G. A., \& Mello, M. A. (2011). Exercise and spirulina control non-alcoholic hepatic steatosis and lipid profile in diabetic Wistar rats. Lipids in Health and Disease, 10, 77. https://doi.org/10.1186/1476-511X-10-77 Ngo-Matip, M. E., Pieme, C. A., Azabji-Kenfack, M., Biapa, P. C., Germaine, N., Heike, E., ... Ngogang, J. Y. (2014). Effects of Spirulina platensis supplementation on lipid profile in HIV-infected antiretroviral naive patients in Yaounde-Cameroon: A randomized trial study. Lipids in Health and Disease, 13, 191. https://doi. org/10.1186/1476-511X-13-191

O'Neill, S., \& O'Driscoll, L. (2015). Metabolic syndrome: A closer look at the growing epidemic and its associated pathologies. Obesity Reviews, 16(1), 1-12. https://doi.org/10.1111/obr.12229

Ou, Y., Lin, L., Pan, Q., Yang, X., \& Cheng, X. (2012). Preventive effect of phycocyanin from Spirulina platensis on alloxan-injured mice. Environmental Toxicology and Pharmacology, 34(3), 721-726. https:// doi.org/10.1016/j.etap.2012.09.016

Pak, W., Takayama, F., Mine, M., Nakamoto, K., Kodo, Y., Mankura, M., ... Mori, A. (2012). Anti-oxidative and anti-inflammatory effects of spirulina on rat model of non-alcoholic steatohepatitis. Journal of Clinical Biochemistry and Nutrition, 51(3), 227-234. https://doi.org/10.3164/ jcbn.12-18

Pessayre, D. (2007). Role of mitochondria in non-alcoholic fatty liver disease. Journal of Gastroenterology and Hepatology, 22(Suppl 1), S20S27. https://doi.org/10.1111/j.1440-1746.2006.04640.x

Price, C. T., Koval, K. J., \& Langford, J. R. (2013). Silicon: A review of its potential role in the prevention and treatment of postmenopausal osteoporosis. International Journal of Endocrinology, 2013, 316783. https://doi.org/10.1155/2013/316783

Price, C. T., Langford, J. R., \& Liporace, F. A. (2012). Essential nutrients for bone health and a review of their availability in the average North American diet. The Open Orthopaedics Journal, 6, 143-149. https:// doi.org/10.2174/1874325001206010143

Qi, S., \& Zheng, H. (2017). Combined effects of phytoestrogen genistein and silicon on ovariectomy-induced bone loss in rat. Biological Trace Element Research, 177(2), 281-287. https://doi.org/10.1007/ s12011-016-0882-1

Raza, H., John, A., \& Howarth, F. C. (2015). Increased oxidative stress and mitochondrial dysfunction in Zucker diabetic rat liver and brain. Cellular Physiology and Biochemistry, 35(3), 1241-1251. https://doi. org/10.1159/000373947

Reagan-Shaw, S., Nihal, M., \& Ahmad, N. (2008). Dose translation from animal to human studies revisited. The FASEB Journal, 22(3), 659-661. https://doi.org/10.1096/fj.07-9574LSF

Rustin, P., Chretien, D., Bourgeron, T., Gerard, B., Rotig, A., Saudubray, J. M., \& Munnich, A. (1994). Biochemical and molecular investigations in respiratory chain deficiencies. Clinica Chimica Acta, 228(1), 35-51. https://doi.org/10.1016/0009-8981(94)90055-8

Saito, T., Toriniwa, Y., Ishii, Y., Uemura, A., Miyajima, K., Uno, K., ... Ohta, T. (2018). Hepatic lesions induced by feeding Western diets to Zucker fatty rats, an insulin-resistant model. Journal of Toxicologic Pathology, 31(4), 283-291. https://doi.org/10.1293/tox.2018-0016

Simon, J. P., Baskaran, U. L., Shallauddin, K. B., Ramalingam, G., \& Evan Prince, S. (2018). Evidence of antidiabetic activity of Spirulina fusiformis against streptozotocin-induced diabetic Wistar albino rats. 3 Biotech, 8(2), 129. https://doi.org/10.1007/s13205-018-1156-8

Srere, P. (1969). Citrate synthase. Methods in Enzymology, 13, 3-11.

Sunderman, F. W. Jr, Marzouk, A., Hopfer, S. M., Zaharia, O., \& Reid, M. C. (1985). Increased lipid peroxidation in tissues of nickel chloridetreated rats. Annals of Clinical and Laboratory Science, 15(3), 229-236.

Tariq, Z., Green, C. J., \& Hodson, L. (2014). Are oxidative stress mechanisms the common denominator in the progression from hepatic steatosis towards non-alcoholic steatohepatitis (NASH)? Liver International: Official Journal of the International Association for 
the Study of the Liver, 34(7), e180-e190. https://doi.org/10.1111/ liv. 12523

Vide, J., Bonafos, B., Fouret, G., Benlebna, M., Poupon, J., Jover, B., ... Coudray, C. (2018). Spirulina platensis and silicon-enriched spirulina equally improve glucose tolerance and decrease the enzymatic activity of hepatic NADPH oxidase in obesogenic diet-fed rats. Food and Function, 9, 6165-6178. https://doi.org/10.1039/c8fo02037j

Vidé, J., Romain, C., Feillet-Coudray, C., Bonafos, B., Cristol, J. P., Fouret, G., ... Gaillet, S. (2015). Assessment of potential toxicological aspects of dietary exposure to silicon-rich spirulina in rats. Food and Chemical Toxicology, 80, 108-113. https://doi.org/10.1016/j.fct.2015.02.021. S0278-6915(15)00067-8 [pii]

Vidé, J., Virsolvy, A., Romain, C., Ramos, J., Jouy, N., Richard, S., ... Rouanet, J.-M. (2015). Dietary silicon-enriched spirulina improves early atherosclerosis markers in hamsters on a high-fat diet. Nutrition, 31(9), 1148-1154. https://doi.org/10.1016/j.nut.2015.03.014. S0899-9007(15)00164-1 [pii]

Wharton, D., \& Tzagoloff, A. (1967). Cytochrome oxidase from beef heart mitochondria. Methods in Enzymology, 10, 245-250.

Witko-Sarsat, V., Friedlander, M., Nguyen Khoa, T., Capeillere-Blandin, C., Nguyen, A. T., Canteloup, S., ... Descamps-Latscha, B. (1998). Advanced oxidation protein products as novel mediators of inflammation and monocyte activation in chronic renal failure. The Journal of Immunology, 161(5), 2524-2532.

Yagi, K. (1984). Assay for blood plasma or serum. Methods in Enzymology, 105, 328-331.

Yigit, F., Gurel-Gurevin, E., Isbilen-Basok, B., Esener, O. B., Bilal, T., Keser, O., ... Ikitimur-Armutak, E. I. (2016). Protective effect of Spirulina platensis against cell damage and apoptosis in hepatic tissue caused by high fat diet. Biotechnic and Histochemistry, 91(3), 182-194. https:// doi.org/10.3109/10520295.2015.1114142

Yousefi, R., Mottaghi, A., \& Saidpour, A. (2018). Spirulina platensis effectively ameliorates anthropometric measurements and obesity-related metabolic disorders in obese or overweight healthy individuals: A randomized controlled trial. Complementary Therapies in Medicine, 40, 106-112. https://doi.org/10.1016/j.ctim.2018.08.003

Zeinalian, R., Farhangi, M. A., Shariat, A., \& Saghafi-Asl, M. (2017). The effects of Spirulina Platensis on anthropometric indices, appetite, lipid profile and serum vascular endothelial growth factor (VEGF) in obese individuals: A randomized double blinded placebo controlled trial. BMC Complementary and Alternative Medicine, 17(1), 225. https:// doi.org/10.1186/s12906-017-1670-y 